\title{
The Efficacy of Transfer of Learning and Retention with Short-Term Auditory Training: Evidences from Auditory Evoked Potential and Behavioral Tests
}

\author{
Sulin Park', Junghwa Bahng ${ }^{1,2}$ \\ 'Department of Audiology and Speech-Language Pathology, Hallym University of Graduate Studies, Seoul, Korea \\ ${ }^{2}$ HUGS Center for Hearing and Speech Research, Seoul, Korea
}

\author{
청성유발반응과 행동검사를 이용한 단기 청능훈련의 학습전이 및 유지 효과에 관한 연구 \\ 박 수 린 ${ }^{1} \cdot$ 방 정 화1,2 \\ 한림국제대학원대학교 청각언어치료학과', 한림청각언어연구소 ${ }^{2}$
}

\begin{abstract}
Purpose: The purpose of this study was to investigate whether short-term auditory training is associated with transfer of learning and retention through behavioral and auditory evoked potential tests the efficacy of short-term auditory training the efficacy. Methods: A total of twenty adult listeners with normal-hearing participated. Among them, eleven participants were randomly assigned as the experimental group. Two pairs of synthesized consonant-vowel (CV) were used, and only one pair of CV was used for the 20-minute auditory training. For the experimental group, behavioral tests and the mismatch negativity (MMN) were assessed using two pairs of $C V$ sounds before and right after the auditory training. For the control group, behavioral and MMN were assessed twice with a 20-minute interval, without any auditory training. Also, all the tests were reassessed in one week after the training only for the experimental group. Results: In the experimental group, scores of the behavioral test increased significantly after the short auditory training for both stimuli sets (trained and untrained CV pairs). Onset latency and duration of MMN were significantly changed when elicited by both stimuli sets. Also, behavioral and $\mathrm{MMN}$ results were not significantly changed in one week after the auditory training. There were no significant changes in behavioral scores and onset latency and duration of $\mathrm{MMN}$ for the experimental group. Conclusion: The present findings support that short-term auditory training produced significant training effects in terms of transfer of learning and retention.
\end{abstract}

Key Words: Auditory training, Mismatch negativity, Transfer of learning, Retention effect.

Received: August 27, 2019 / Revised: September 20, 2019 / Accepted: October 4, 2019

Correspondence: Junghwa Bahng, Department of Audiology and Speech-Language Pathology, Hallym University of Graduate Studies, 427 Yeoksam-ro, Gangnam-gu, Seoul 06197, Korea

Tel: +82-70-8680-6933 / Fax: +82-2-3453-6618 / E-mail: bahng.jh@gmail.com

\section{INTRODUCTION}

청성유발전위 평가(auditory evoked potential)의 결과는 청 각 처리(auditory processing)를 이해할 수 있으며, 행동평가 결 과를 보완하여 사용 가능한 평가이다. 특히 청성유발전위 중 후기반응(late auditory evoked potential)검사는 중추청각신경

(c) This is an Open Access article distributed under the terms of the Creative Commons Attribution Non-Commercial License (https://creativecommons.org/licenses/by-nc/4.0) which permits unrestricted non-commercial use, distribution, and reproduction in any medium, provided the original work is properly cited.
계에서 소리의 변별, 통합, 그리고 집중에 관련한 대뇌청각피질 활동을 측정할 수 있는 특징이 있다(de Melo et al., 2018). 후기 청성유발반응 중 음전위 부정합(mismatch negativity, $\mathrm{MMN}$ ) 은 무작위로 제시된 자극음의 반응에서 일정하게 제시되는 자 극음의 반응을 차이에 의해 계산된 음(negative)의 방향 파형 에서 찾을 수 있다(Garrido et al., 2009). MMN은 청각기능의 전주의적 인지(pre-attentive cognition) 작용과 관련이 있으며 이러한 청각기능의 작용은 청각피질(auditory cortex)의 원시적 지능을 반영한다(Naätänen et al., 2001). MMN은 학습을 통 
하여도 변화가 일어나며(Tremblay et al., 1997), 언어의 음향적 단서 변화에 의한 신경생리학적 변화를 확인할 수 있다(Kraus et al., 1995).

청각 시스템은 새로운 신호에 대한 경험과 학습을 통해 재구 성되고 이러한 가소성은 새로운 환경이나 상황에 대처할 수 있 는 기반이 된다(Kompus \& Westerhausen, 2018). 많은 연구에 따르면 말소리에 대한 인식은 훈련을 통해 향상될 수 있으며 (Tremblay et al., 2001; Wright \& Zhang, 2009), 이러한 훈련 은 새로운 신호를 듣기 연습을 통해 소리 듣기 방법을 뇌에 익 히는 과정으로 신경가소성(neural plasticity)의 가속화를 기대 할 수 있다(Wright \& Zhang, 2009). 훈련을 통하여 전기생리 학적 변화를 관찰한 연구를 살펴보면 훈련을 통하여 음성발성 시간(voice onset time)이 다른 두 음을 구별하는 능력이 행동 검사 결과에서도 증가하게 나타났을 뿐만 아니라 $\mathrm{MMN}$ 의 잠 복기도 훈련 후 변화하였으며(Tremblay et al., 1997), 후기 청 성유발전위의 N1-P2 진폭 또한 증가하여(Tremblay et al., 2001), 청능훈련의 결과 신경활동을 변화할 수 있음을 확인하 였다. 이러한 신경활동의 변화가 비슷한 음향학적 특징을 가졌 지만 훈련하지 않은 자극음에도 훈련 효과가 전이되는 것을 확 인하기 위한 실험에서는 5 일간의 훈련으로 훈련하지 않은 음을 자극음으로 사용하였을 때 $\mathrm{MMN}$ 과 행동검사에서 변화를 관 찰할 수 있어 학습전이(transfer of learning)가 될 수 있음을 시사하였다(Tremblay et al., 1997). 또한 언어 자극이 아닌 순 음을 이용하여 주파수의 작은 차이를 변별하도록 4 12일간 훈 련하여 훈련한 주파수가 아닌 다른 주파수로 학습전이가 일어 나 변별능력의 향상을 보였다고 보고한 연구 또한 청능훈련에 서 훈련으로 사용하지 않은 소리에도 훈련 효과가 전이될 수 있다는 가능성을 증명하였다(Wright \& Zhang, 2009). 행동검 사와 청성유발전위검사를 통하여 청능훈련의 효과를 측정한 연구를 보면 정상청력을 가진 대상자뿐만 아니라 학습장애 아 동(Russo et al., 2005), 청각처리 장애인(auditory processing disorders) (de Melo, 2018), 노인성 난청인(Asal et al., 2018) 등 을 대상으로 한 연구에서도 같은 결과를 보였다.

앞서 언급한 청능훈련에 관한 선행연구에서는 훈련의 기간 을 짧게는 4일, 길게는 12 일까지 여러 회기에 걸쳐 실시하였다. 이러한 청능훈련의 효과는 단기로 실시한 청능훈련을 이용한 연구에서도 행동검사 및 신경반응검사에서의 변화를 관찰할 수 있었다. 순음의 두 주파수 차이를 변별능력은 2회기의 훈련 만으로 변별능력이 개선되었으며(Amitay et al., 2006), 또 다른 연구에서는(Tremblay et al., 1997) 서로 다른 음성발성시간을 가진 두 가지 자극을 변별하도록 할 때 훈련 1일 차에 신경생리 학적 변화를 관찰하였다. Ben-David et al.(2011)은 음성발성시 간이 다른 두 음성 $/ \mathrm{ba} /$ 와 $/ \mathrm{mba} /$ 를 1 시간 동안 청능훈련을 한
후 N1-P2의 진폭을 훈련 전과 비교한 결과 유의하게 진폭이 증가함을 보고하여 청능훈련의 효과를 증명하였다. Han et al. (2013)의 연구에서 정상청력을 가진 성인 대상으로 20 분 동안 단기 변별훈련을 실시하였고 훈련 후에 $\mathrm{MMN}$ 의 시작 잠복기 (onset latency)가 빨라지고 행동검사 결과도 향상되었다. 선행 연구들의 결과는 짧은 시간만의 훈련으로 훈련한 음에 대한 단 기기억력에 의하여 신경이 활성화되고 이로 인해 뇌 활동의 변 화가 일어날 수 있다는 증거라고 할 수 있다.

집중적인 듣기훈련인 청능훈련에서는 모든 소리를 듣고 훈련 할 수 없기 때문에 학습전이가 필요할 뿐만 아니라 청능훈련 효과의 유지(retention)가 중요하다(Tremblay et al., 1997). 유 지란 청능훈련에서 습득한 지식을 잊지 않고 지속하고 있다는 의미이다. 짧은 시간의 단기 훈련이 단기기억력으로 행동 및 전 기생리적 검사의 변화를 유발하지만, 유지될 수 있는지에 관한 전기생리학적인 연구는 아직 진행된 바가 없다. 본 연구는 Han et al.(2013)에서 진행한 20분간의 단기 청능훈련 후 MMN 결 과 변화와 행동점수 개선을 통해 확인한 단기 청능훈련 효과 연구의 후속연구로 진행하였다. 본 연구에서의 연구 목적은 다 음과 같다. 첫째, 단기 변별청능훈련으로 훈련한 음이 유사한 음향학적 특징을 가진 훈련하지 않은 음으로도 훈련의 효과가 나타나는지, 둘째, 단기 변별청능훈련으로 훈련의 효과가 1 주일 후에도 유지되는지 알아보고자 한다. 청능훈련 효과로 학습전 이와 훈련 효과의 유지를 알아보기 위해서 행동검사와 청성유 발전위 검사인 $\mathrm{MMN}$ 을 이용하였다.

\section{MATERIALS AND METHODS}

\section{연구 대상}

본 연구에서는 정상청력 성인 20명(여: 12 명)이 참여하였다. 대상자들은 모두 대학 이상의 고등교육을 받은 자들로 인지적 인 문제가 없음을 스스로 보고한 자들로 구성하였다. 또한 청 각 실험에 참여했던 경험이 없는 대상자를 선별하였으며 실험 시작 전 연구에 대한 안내를 하였고 실험을 무난히 수행 가능 하다고 판단한 대상자를 참여하도록 하였다. 대상자들은 순음 청력검사에서 $250 \sim 8,000 \mathrm{~Hz}$ 내 전 주파수에서 $20 \mathrm{~dB} \mathrm{HL}$ 이 하의 청력역치를 보이고 고막운동도검사(R26M, Resonance, Gazzaniga, Italy)에서 A형이었다. 순음청력검사는 전기음향적 연간 보정을 실시한 청력검사기(GSI audiostar pro, GrasonStadler, Eden Prairie, MN, USA)를 사용하였다. 모든 대상자 는 중이 질환, 소음 노출, 이독성 약물복용, 신경학적 질환 등 의 이과적, 신경학적 과거 병력과 난청의 가족력이 없는 대상자 로 선정하였다. 모든 대상자는 오른손잡이이며 한국어를 모국 어로 하였다. 20 명의 대상자들은 실험군 11 명과 대조군 9 명으 
로 나뉘었다. 실험군의 평균연령은 26.3세(22 32세), 대조군의 평균연령은 27.4세(23 38세)로 모든 대상자의 평균연령은 26.8세였다.

\section{자극음}

본 연구에서 사용된 자극음은 인위적인 음으로 사람이 발음 할 수 없는 음으로 선택하였다. 자모음(consonant-vowel) 음절 인 마찰음 /su/-/ $\mathrm{u} /$ 와 비슷한 음으로 software cascade/parallel formant synthesizer를 사용하여 만들었고(Klatt, 1980), 훈 련음 쌍의 경우 선행논문에서 사용한 자극음을 사용하였다 (Han et al., 2013). 자극음은 마찰 스펙트럼에서 가장 에너지가
강한 부분인 극점 주파수(pole frequency)와 자음과 모음 사이 의 F2 포먼트 전이 주파수(formant transitional frequency)를 조절하였다. 훈련음의 선정은 Han et al.(2013)에서 사용한 훈련 음을 동일하게 선정하였다. Han et al.(2013)에서는 대상자들이 변별하지 못하는 두 쌍의 자극음을 선행논문의 결과를 토대로 선정하였다(Hedrick et al., 2011; Lee \& Bahng, 2012). 연구에 사용한 음에 대한 스펙트로그램은 Figure 1과 2에 제시하였다.

\section{훈련 자극음}

훈련음은 2,450 Hz의 극점 주파수와 $1,200 \mathrm{~Hz}$ 포먼트 전이 주파수인 /su/ 자극음, $3,450 \mathrm{~Hz}$ 극점 주파수와 $1,800 \mathrm{~Hz}$ 포먼
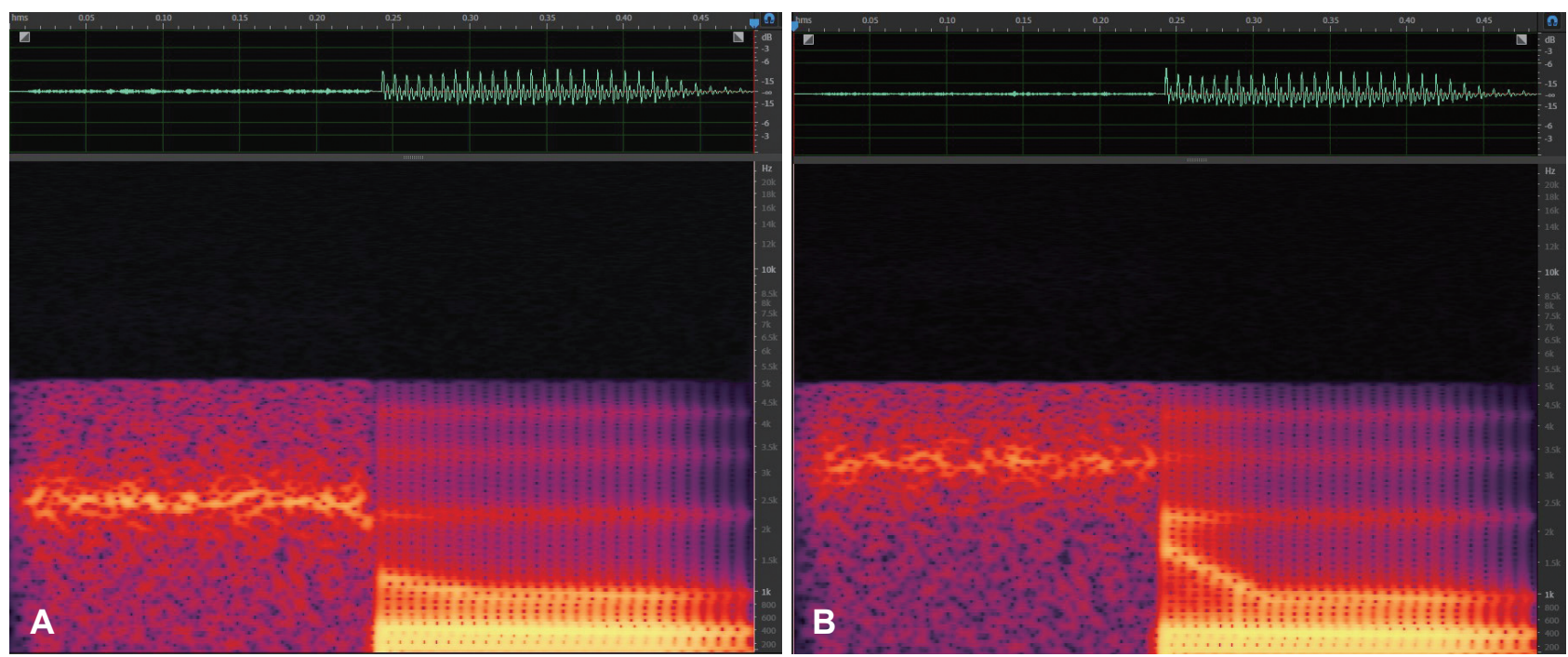

Figure 1. The spectrum and spectrogram of trained stimuli. The stimuli in (A) has $2,450 \mathrm{~Hz}$ fricative frequency with $1,200 \mathrm{~Hz}$ formant frequency. The stimuli in (B) has $3,450 \mathrm{~Hz}$ fricative frequency with $1,800 \mathrm{~Hz}$ formant frequency. $\mathrm{X}$-axis indicates time. $Y$ axis of upper panel is amplitude, and $y$-axis of down panel is frequency.
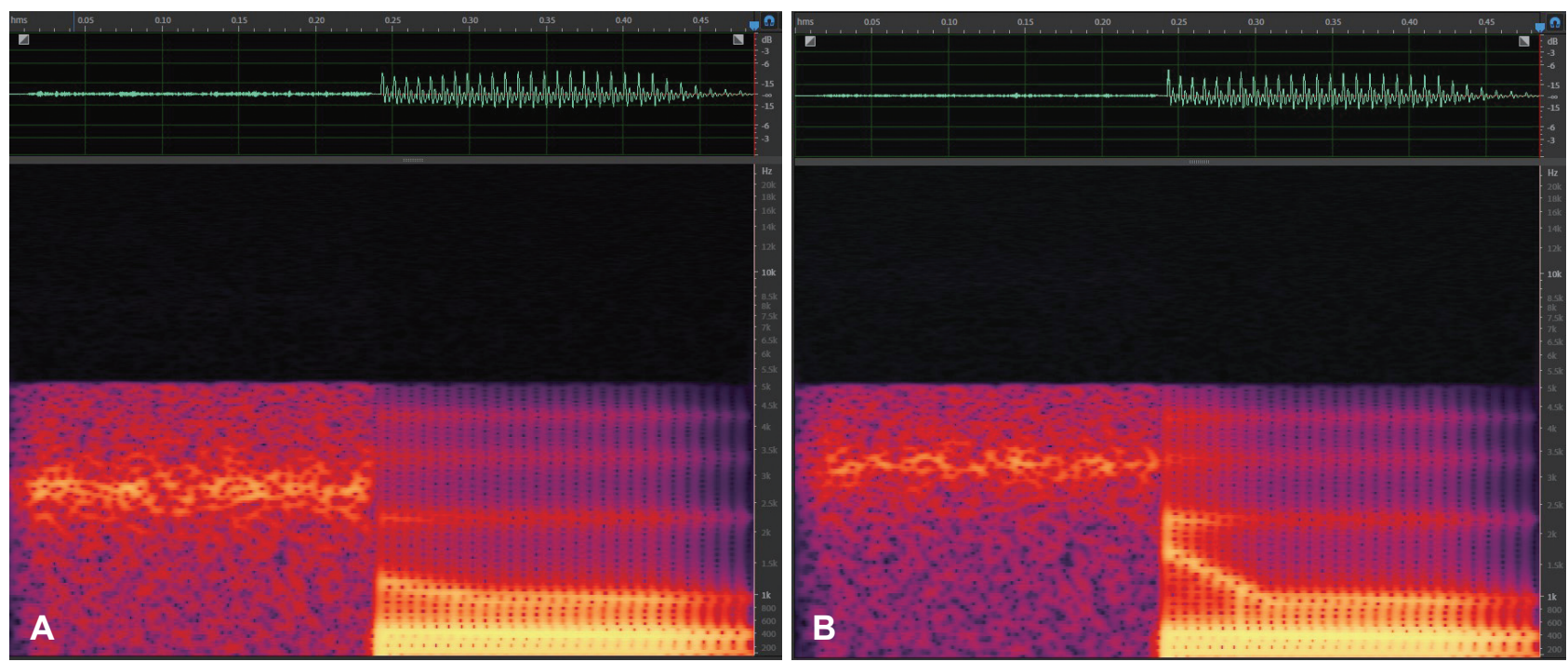

Figure 2. The spectrum and spectrogram of untrained stimuli. The stimuli in (A) has $2,700 \mathrm{~Hz}$ fricative frequency with $1,200 \mathrm{~Hz}$ formant frequency. The stimuli in (B) has $3,200 \mathrm{~Hz}$ fricative frequency with $1,800 \mathrm{~Hz}$ formant frequency. X-axis indicates time. $\mathrm{Y}$ axis of upper panel is amplitude, and $y$-axis of down panel is frequency. 
트 전이 주파수인 $/ \mathrm{su} /$ 자극음을 선택했다. 훈련 자극은 $/ \mathrm{su} /$ (T1)와 / $/ \mathrm{u} /(\mathrm{T} 2$ ) 쌍을 사용하였다(Figure 1).

\section{비훈련 자극음}

학습전이를 확인하기 위한 비훈련음은 $2,700 \mathrm{~Hz}$ 의 극점 주 파수와 $1,200 \mathrm{~Hz}$ 의 포먼트 전이 주파수인 /su/ 자극음, 3,200 $\mathrm{Hz}$ 의 극점 주파수와 $1,800 \mathrm{~Hz}$ 의 포먼트 전이 주파수인 $/ \mathrm{Ju} /$ 자극음을 선택했다. 비훈련 자극은 $/ \mathrm{su} /(\mathrm{U} 1)$ 와 $/ \mathrm{fu} /(\mathrm{U} 2)$ 쌍을 사용하였다(Figure 2).

\section{행동검사}

행동검사는 조용한 환경에서 실시하였다. 각각의 대상자들 에게 스피커를 통해 가장 편안한 소리 크기로 자극음이 제시되 었다. 훈련 자극음 $\mathrm{T} 1, \mathrm{~T} 2$ 각각 20 회, U1, U2 각각 20회로 자 극음을 쌍별로 제시하여 검사를 실시하였다. 두 음을 대상자 들은 무작위로 제시되는 각 자극음 쌍을 듣고 같은지 다른지 변별하여 선택하였다. 예를 들어 T1-T1, T2-T1, T2-T2, T1-T2 등이 제시되면 대상자들은 두 음이 "같다" 혹은 “다르다"를 답 하여 두 음을 변별할 수 있는지 없는지를 평가하였다.

\section{청성유발전위검사}

$\mathrm{MMN}$ 검사에서 대상자들이 검사가 진행되는 동안 오른쪽 귀로 제시되는 자극음에 집중하지 않도록 다른 생각을 하거나 구구단을 계속적으로 속으로 외우게 하였고 침대에 편안한 자 세로 누워 $\mathrm{MMN}$ 검사를 실시하였다.

\section{$\mathrm{MMN}$ 파라미터}

$\mathrm{MMN}$ 은 2 채널로 $\mathrm{Cz}$ 에 기준 전극(reference electrode), $\mathrm{A} 1$ 과 A2에 활성 전극(active electrode)을 각각 위치하였다(BioLogic Navigator Pro system, Bio-Logic Co., Willow Hill, PA, USA). 자극의 주파수와 bit는 각 $48,000 \mathrm{~Hz}$ 와 16 bit, mono sound로 조정하였다. 자극의 지속 시간은 $500 \mathrm{msec}$ 였고 자극 간격(inter-stimulus interval)은 $1,000 \mathrm{msec}$ 였다. 표준 자극 $/ \mathrm{su} /$ 와 비표준 자극 $/ \mathrm{Su} /$ 가 5:1의 비율로 제시되는 oddball paradigm을 사용하였다. 자극은 우측 귀에 삽입형 이어폰을 통해 $75 \mathrm{~dB}$ SPL로 대략 350회 제시되었다. 반응 필터링은 $1 \sim 100 \mathrm{~Hz}$, 이득은 50,000이고 0 500 msec 동안 기록하였다. 잡파(artifacts)는 $95 \mathrm{mV}$ 이상일 경우 제거되었다.

\section{실험 절차}

본 연구는 조용한 환경에서 실시하였다. 먼저 실험군과 대조 군은 모두 사전평가로 $\mathrm{MMN}$ 과 행동검사를 실시하였다. 이때 사용한 자극음은 T1-T2, U1-U2를 사용하였다. 사전평가 후
실험군은 20분간 청능훈련 자극음 T1-T2만을 사용하였으며, 이때 무작위로 듣고 제시된 자극음 쌍이 같은지 다른지 구분하 거나 각 자극음이 어떤 자극음인지 선택하는 단기 음소변별 청 능훈련을 반복 실시하였고 이에 대한 피드백을 받았다. 대조군 의 경우 청능훈련 대신에 20 분간 간단한 동영상을 보는 등 쉬 는 시간을 가졌다.

실험군의 경우 20 분간의 청능훈련을, 대조군의 경우 20 분간 의 쉬는 시간을 가진 후 청능훈련 효과를 확인하기 위해 두 번 째 MMN과 행동검사를 무작위 순서로 실시하였다. 실험군은 훈련 일주일 후 동일한 $\mathrm{MMN}$ 과 행동검사를 실시하였다.

\section{자료 분석}

본 연구결과의 통계 분석을 위해 SPSS Statistics (Ver. 25.0, IBM Corp., Armonk, NY, USA)를 사용하였다. 각 그룹의 행 동검사와 $\mathrm{MMN}$ 에서 훈련 자극, 비훈련 자극에서의 점수, 시작 잠복기, 지속 시간을 훈련 전후 비교를 위해 이원분산분석 [two-way analysis of variance (ANOVA) with repeated measures]을 시행하였고 Bonferroni correction으로 다중비교를 실 시하였다. 실험군에서 훈련 후와 1 주일 후 유지 효과를 비교하 기 위해 반복측정 이원분산분석(two-way ANOVA with repeated measures)을 시행하였다. $\mathrm{MMN}$ 의 여러 분석 컴포넌트 중 시작 잠복기와 지속 시간은 Han et al.(2013)의 연구에서 청능 훈련 전후에 이 두 가지 컴포넌트가 유의하게 달라짐을 밝혀 본 연구에서도 동일하게 시작 잠복기와 지속 시간을 분석하였다. 모든 통계 분석은 유의 수준 0.05 미만으로 검증하였다.

\section{RESULTS}

본 연구에서는 건청 성인을 대상으로 1 회기의 짧은 시간 동안 자극음을 변별하는 듣기훈련을 통하여 훈련하지 않은 자극음 에 대한 훈련 효과의 학습전이 및 유지를 알아보고자 하였다.

\section{행동검사 결과}

훈련 전후 행동검사 점수 평균이 실험군이 훈련 자극에서 청 능훈련 전 45 95\%[mean $=75 \%$, standard deviation $(\mathrm{SD})=$ 16.99], 청능훈련 후 75 100\%(mean $=95 \%, \mathrm{SD}=7.12$ ), 청능훈 련 일주일 후 70 100\%(mean $=90 \%, \mathrm{SD}=9.73$ )였다. 비훈련 자극에서는 청능훈련 전 45 90\%(mean $=68 \%, \mathrm{SD}=16.10$ ), 청 능 훈련 후 65 100\%(mean $=89 \%, \mathrm{SD}=8.55)$, 훈련 일주일 후 70 100\%(mean $=86 \%, \mathrm{SD}=10.82$ )였다.

대조군은 사실 훈련을 받지 않았기에 훈련 자극에서 훈련 전 60 95\% (mean $=83 \%, \mathrm{SD}=12.04)$, 훈련 후 55 95\%(mean = $82 \%, \mathrm{SD}=12.16$ )였다. 비훈련 자극에서는 훈련 전 50 95\% 
$($ mean $=69 \%, \mathrm{SD}=16.89)$, 훈련 후 50 95\% $($ mean $=70 \%$, $\mathrm{SD}=15.40$ )였다(Figure 3).

행동검사에서 그룹별 훈련 전후의 변화를 확인하기 위해 이 원분산분석(two-way ANOVA with repeated measures)을 실 시했다. 개체 내 요인은 검사 시기(전, 후, 후속 검사), 자극음 종 류(훈련음, 비훈련음)였다. 분석 시 구형성 검정을 위반하여 Greenhouse-Geisser를 선택하였고 다중비교는 Bonferroni correction으로 확인하였다. 그룹별 결과는 다음과 같다.

\section{실험군}

실험군은 행동검사 점수가 검사 시기(전, 후, 후속 검사)에서 유효한 주 효과를 보였다 $[\mathrm{F}(2,20)=35.686, p=0.000]$. 자극음 종류(훈련음, 비훈련음)에서도 유효한 주 효과를 보였다 $[\mathrm{F}(1,10)$ $=6.752, p=0.027$. 다중비교 결과 훈련 전후는 유의한 차이를 보였고 $(p=0.000)$, 훈련 후와 후속검사에서는 유의한 차이 $(p=$ 0.092), 훈련 후 증가한 변별능력이 일주일 후까지 유지됨을 확 인하였다.

\section{대조군}

대조군은 행동검사 점수의 결과에서 전검사와 20 분 후의 검 사에서 유의한 차이를 보이지 않았다 $[\mathrm{F}(1,8)=0.442, p=0.525]$. 그러나 훈련 자극과 비훈련 자극에서 유의한 차이를 보여 $[\mathrm{F}(1$, 8) $=9.941, p=0.014]$, 두 쌍의 자극음의 변별력이 유의한 차이 가 있는 것으로 나타났다. 그러나 20분 간격으로 실시한 두 번 의 검사가 유의하게 다르지 않은 것으로 나타나 두 쌍의 자극음 의 변별력은 향상되지 않고 유지되는 것으로 나타났다.

\section{청성유발전위 결과}

훈련 전후 $\mathrm{MMN}$ 시작 잠복기 평균이 훈련 자극에서 실험군 (experiment group)이 훈련 전 $158.851 \mathrm{msec}$ 에서 훈련 후 $147.214 \mathrm{msec}$ 로 감소하였다. 대조군(control group)은 훈련 전 $179.528 \mathrm{msec}$ 에서 훈련 후 $183.574 \mathrm{msec}$ 로 증가하였다. 비훈련 자극에서 실험군은 $157.719 \mathrm{msec}$ 에서 $138.223 \mathrm{msec}$ 로 감소하 였고 대조군은 $165.184 \mathrm{msec}$ 에서 $172.354 \mathrm{msec}$ 로 증가하였다.

$\mathrm{MMN}$ 지속 시간은 훈련 자극에서 실험군은 훈련 전 82.428 $\mathrm{msec}$ 에서 훈련 후 $107.130 \mathrm{msec}$ 로 증가하였고 대조군은 81.428 $\mathrm{msec}$ 에서 $69.633 \mathrm{msec}$ 로 감소하였다. 비훈련 자극에서도 실험 군과 대조군의 훈련 전후 지속 시간의 변화가 훈련 자극과 동 일하였다(Figure 4).

$\mathrm{MMN}$ 결과에서 그룹별 훈련 전후의 변화를 확인하기 위해 이원분산분석을 실시했다. $\mathrm{MMN}$ 의 요소인 시작 잠복기와 지속 시간별로 개체 내 요인은 검사 시기(전, 후, 후속 검사), 자극음 종류(훈련음, 비훈련음)였다. 구형성 검정을 위반하여 Greenhouse-Geisser를 선택하였고 다중비교는 Bonferroni correction으로 확인하였다. 그룹별 결과는 다음과 같다.

\section{실험군}

실험군은 $\mathrm{MMN}$ 시작 잠복기에서는 검사 시기의 주 효과는 유의하지 않았다 $[\mathrm{F}(2,20)=4.289, p=0.056]$. 또한 자극음 종 류에 따른 주 효과 또한 유효하지 않았다 $[\mathrm{F}(1,10)=0.401, p=$ 0.541]. 그러나 $\mathrm{MMN}$ 시작 잠복기의 결과를 다중비교 결과에 서는 훈련 전후는 유의한 차이를 보였고 $(p=0.001)$ 훈련 후와 후속검사에서는 유의한 차이를 보이지 않았다 $(p=1.000)$. 훈련 전보다 훈련 후의 시작 잠복기는 유의하게 변화하였고 훈련 후 와 1 주일에 유의한 차이가 없는 것으로 보아 훈련 효과가 유지

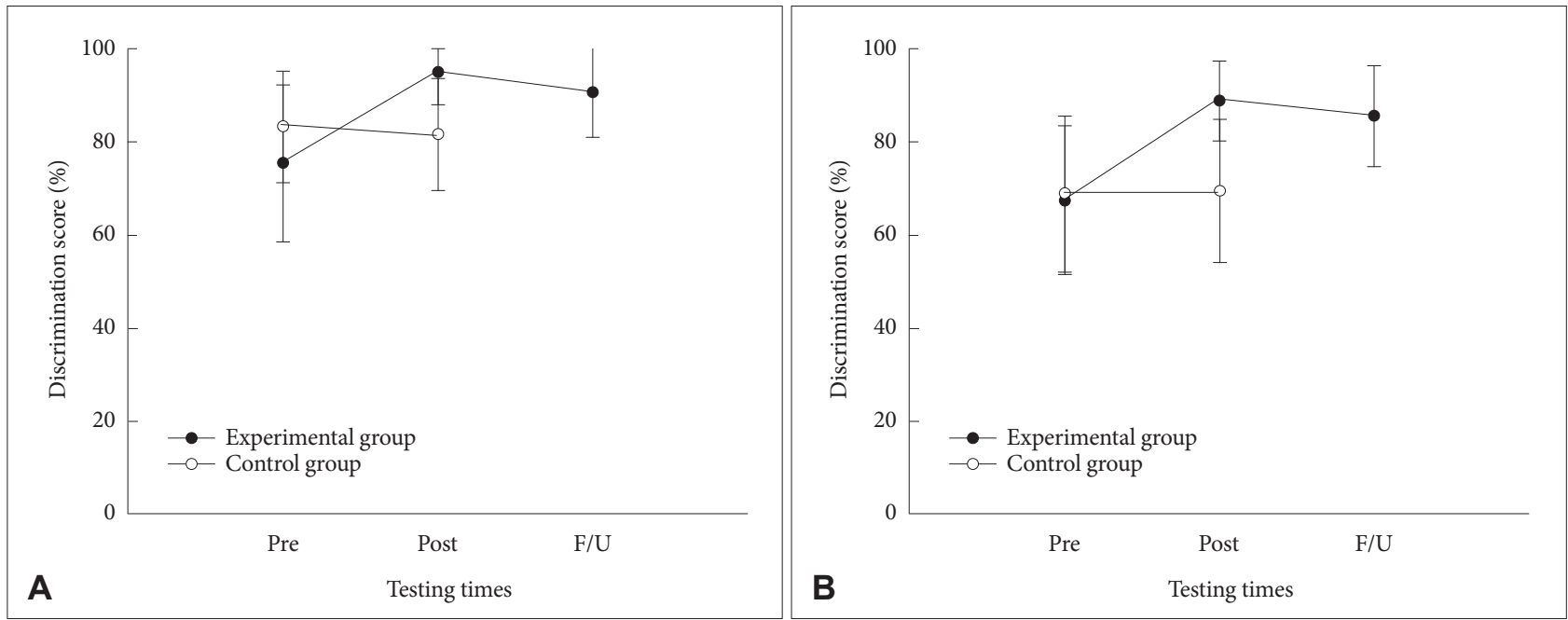

Figure 3. Comparison of discrimination scores for experimental and control groups as the testing times (e.g., pre-, post-, and F/U auditory trainings for experimental group, 1 st and 2 nd tests for control group), when using trained stimuli (A) and untrained stimuli (B). F/U: follow-up. 

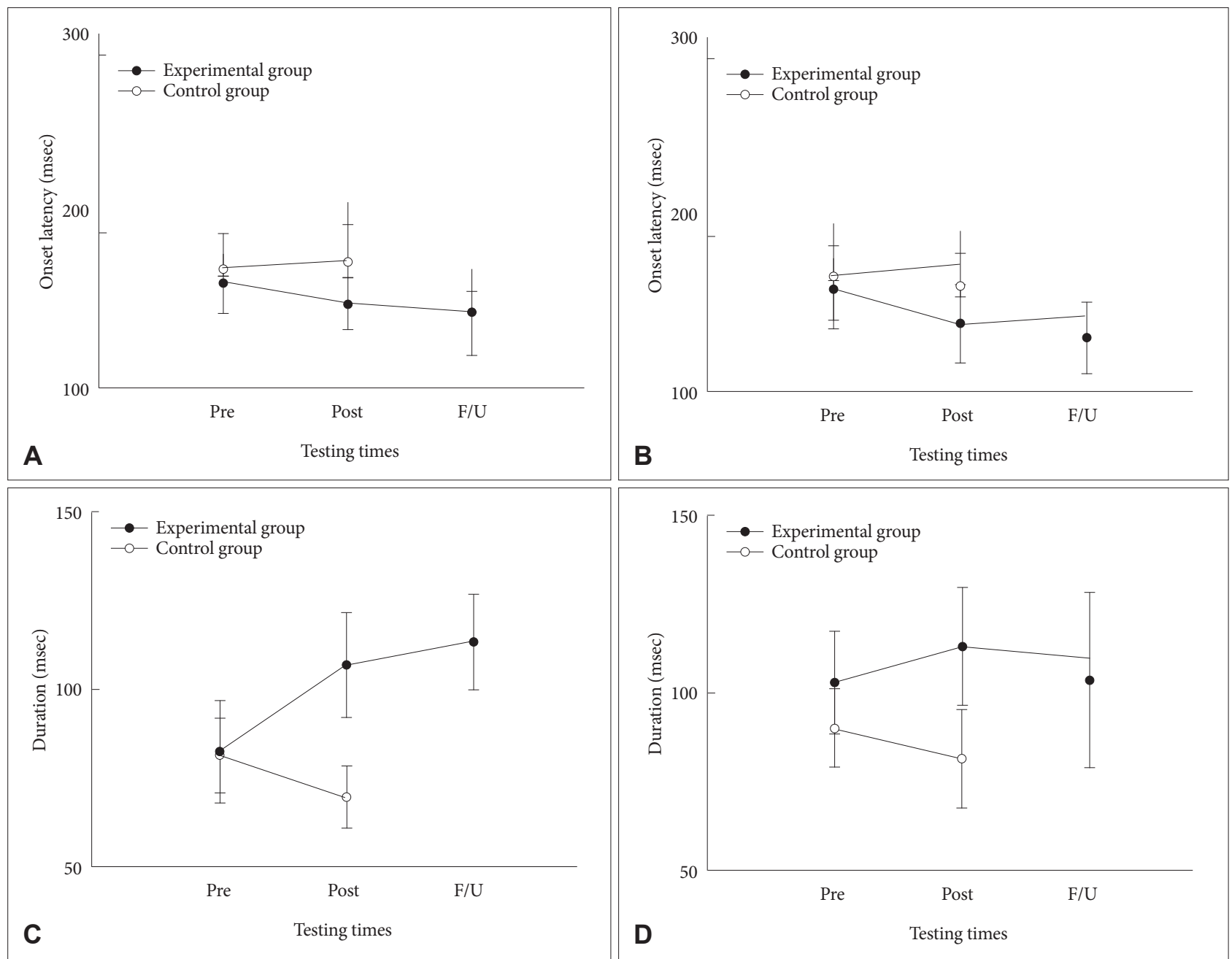

Figure 4. Comparison of mismatch negativity onset latency $(A, B)$ and duration results (C, D) for experimental and control groups as the testing times (e.g., pre-, post-, and F/U auditory trainings for experimental group, 1st and 2nd tests for control group), when using trained stimuli $(A, C)$ and untrained stimuli $(B, D)$. F/U: follow-up.

됨을 보였다.

$\mathrm{MMN}$ 지속 시간은 검사 시기의 주 효과가 유의하였고[F(2, 20) $=8.812, p=0.005]$, 자극음에 따른 주 효과는 유의하지 않 았다 $[\mathrm{F}(1,10)=2.919, p=0.118]$. 다중비교 결과에서는 훈련 전 후는 유의한 차이를 보였으나 $(p=0.009)$ 훈련 후와 후속 사이 의 관계는 유의하지 않은 차이 $(p=1.000)$ 를 보여 시작 잠복기와 같이 훈련 효과가 유지되는 것으로 나타났다.

\section{대조군}

대조군은 $\mathrm{MMN}$ 시작 잠복기에서는 검사 시기에 따른 주 효 과는 유의하지 않았다 $[\mathrm{F}(1,8)=1.535, p=0.251]$. 훈련 자극음 주 효과 또한 유의하지 않았다 $[\mathrm{F}(1,8)=1.354, p=0.278]$.

$\mathrm{MMN}$ 지속 시간의 결과 검사 시기의 주 효과가 나타났으며 $[\mathrm{F}(1,8)=7.383, p=0.026]$ 자극음에 따른 주 효과도 유의함을 보였다 $[\mathrm{F}(1,8)=19.341, p=0.002]$. 이 결과는 대조군의 훈련
쌍과 비훈련 쌍의 자극음에서 $\mathrm{MMN}$ 지속 시간이 유의하게 줄 어들었음을 보여준다. Figure 2는 실험군과 대조군의 자극음 종류별 훈련 전후 $\mathrm{MMN}$ (시작 잠복기, 지속 시간) 결과 변화를 보여준다.

본 연구에서 실시한 행동검사와 $\mathrm{MMN}$ 검사결과 간 상관관 계를 확인하기 위해 이변량 상관계수(bivariate correlation)를 실시했다. 변수는 행동검사와 $\mathrm{MMN}$ 지속 시간의 훈련 전후의 결과 차이였다. 상관계수는 Pearson (n)으로 기본 설정하였다. 행동검사와 $\mathrm{MMN}$ 검사 간 상관관계는 훈련음과 비훈련음 모 두 상관계수가 0.02 미만으로 상관관계가 없었다(훈련음: $\mathrm{r}=$ -0.254 , 비훈련음: $r=-0.008)$.

\section{DISCUSSIONS}

본 연구에서는 정상청력의 성인을 대상으로 첫째, 단기 청능 
훈련을 통한 학습전이와 둘째, 훈련 효과의 유지를 행동검사와 전기생리검사인 $\mathrm{MMN}$ 을 통하여 알아보고자 하였다.

\section{단기 청능훈련의 학습전이 효과}

본 연구의 결과 실험군의 행동검사 결과가 훈련 전보다 훈련 후에 유의미하게 증가하였다. 반면에 대조군의 경우는 훈련 전 과 후의 유의한 변화가 없었다. 이러한 결과는 음향적 특성이 비슷하지만 훈련하지 않은 자극음의 쌍에서도 동일하게 나타 났다. 이 결과를 통해서 20 분의 짧은 청능훈련이 행동검사의 변화를 일으키기에 충분하였고 이러한 향상된 능력은 학습하 지 않은 훈련 자극에 학습전이 되었다는 것을 알 수 있다.

전기생리학적인 결과도 행동검사와 동일하게 나타났다. 단기 간의 청능훈련을 실시하고 훈련받지 않은 자극에서도 $\mathrm{MMN}$ 의 시작 잠복기가 감소하고 지속 시간이 증가하는 신경학적 변화 를 보였음을 본 연구결과를 통하여 확인하였다. $\mathrm{MMN}$ 에서 시 작 잠복기는 두 음의 변별하기 시작하는 때를 의미한다. Han et al.(2013)의 연구에서는 시작 잠복기가 빨라지고 끝 잠복기 (offset latency)는 변화가 없어 결과적으로 지속 시간이 증가하 는 결과를 보였다. Naätänen(2008)에 따르면 자극음으로 사용 하는 두 음의 차이가 클수록 잠복기가 빨라진다고 하였다. 본 연구에서도 청능훈련 후 시작 잠복기가 빨라진 것은 두 음의 차이를 식별하는 능력이 커진 것으로 해석할 수 있겠다. $\mathrm{MMN}$ 은 앞선 자극음과 현재 자극음의 차이에 의해서 발현이 되기 때문에 앞선 음을 기억하지 못한다면 현재의 자극음과의 차이 를 변별하지 못하게 된다. 또한 $\mathrm{MMN}$ 의 수행 중에는 제시되는 자극음에 집중하지 않도록 하고 있기에 중추청각능력의 기억력 에 의존하여 발현된다고 할 수 있다. 그러므로 $\mathrm{MMN}$ 은 청각적 기억에 의존한 자동 변화 감지기이며 청각적 감각의 정확성을 보는 객관적인 검사라고 할 수 있다(Naätänen, 2000; Tiitinen et al., 1994). 본 연구의 결과는 훈련을 받은 참가자들이 청각훈 련을 통해 두 자극음의 음향적 차이를 정립하고 기억했으며, 훈 련하지 않은 자극에도 훈련음을 통해 정립한 음향적 차이 변별 능력을 적용하여 학습전이가 나타났음을 알 수 있다. $\mathrm{MMN}$ 의 결과는 음에 대한 기억력의 능력과 연관이 있다(Garrido et al., 2009).

본 연구의 결과는 선행연구의 결과를 뒷받침하고 있다. Tremblay et al.(1997)은 정상청력을 가진 성인의 음성발성시간 이 $-50 \mathrm{~ms}$ 에서 $+50 \mathrm{~ms}$ 까지 변한 것을 식별하도록 10 일 동안 훈련받은 경우, 훈련받지 않은 다른 자극에서도 $\mathrm{MMN}$ 의 시작 잠복기와 지속 시간이 변화했다고 보고하였으며, Kraus et al. (1995)의 어음 자극 /da/의 두 번째, 세 번째 포먼트 전이(formant transition)의 시작 주파수(onset frequency)를 다르게 조절한 두 자극을 구별하도록 훈련한 연구에서도 동일한 결과를 보였
다. 또한 선행연구의 결과에서 변별능력이 더 좋은 피험자는 청 성유발전위에서 짧은 잠복기를 보였고 진폭이 증가하였으며 이 러한 현상은 변별능력이 증가할수록 신경계가 활성화한다는 증거라고 보고하였다(Beauchamp \& Stelmack, 2006; Han et al., 2013; Tremblay et al., 2001). 본 연구의 제한점은 기계 분석의 문제로 $\mathrm{MMN}$ 의 면적을 비교하지 못한 점이다. 또한 Tremblay et al.(1997)은 청각적인 행동능력 변화 이전에 $\mathrm{MMN}$ 의 변화가 선행된다고 보고하였지만 본 연구결과에서는 행동검사와 청성 유발전위검사를 무작위 순으로 검사하였기 때문에 어떠한 변 화가 선행되는지 확인할 수 없었다. 후속연구에서는 이러한 점 을 보완하여 청능훈련의 증거로 제시되어야 할 것이다.

\section{단기 청능훈련의 훈련 효과 유지}

청능훈련의 효과에 관한 행동적 검사의 유지에 관한 연구는 많이 이루어졌지만(Wright \& Zhang, 2009), 객관적인 전기생 리학적인 연구는 이루어지지 않았다. 본 연구에서 단기 청능훈 련의 유지 효과에 관한 실험은 실험군만 참여하였으며 훈련을 받은 이후 1 주일 뒤에 동일하게 행동검사와 $\mathrm{MMN}$ 검사를 훈련 쌍 자극음과 비훈련쌍 자극음을 이용하여 검사하였다. 그 결 과 행동검사와 $\mathrm{MMN}$ 검사 모두 훈련 후 능력이 1 주일까지 유 지되는 것으로 나타났다.

본 연구에서는 음향적 차이를 변별하는 청능훈련으로 한 개 의 쌍만 이용하여 진행하였고 대상자가 모두 20대의 정상청력 을 가진 성인만이 참여하였다. 그리고 실험군을 대상으로 1 주 일 후 재검사를 진행하였다. 그러나 청각적 기억력 수행력이 감 소한 난청인 혹은 노인의 경우나 장기간이 지난 후 재검사를 한 경우에는 본 연구의 결과와는 다른 결과가 도출될 가능성 이 있다. 그러므로 단기훈련의 유지에 관한 청성유발전위에 대 한 연구는 많은 후속연구가 이루어져야 할 것으로 본다.

본 연구의 목적은 단기 청능훈련의 학습전이와 유지 효과를 행동검사와 전기생리학적 검사를 통해서 증명하고자 하였다. 결론적으로 첫째, 매우 짧은 시간의 집중적인 듣기 훈련 또한 생리학적인 변화를 일으키며 학습하지 않은 음에도 그 효과가 전이되어 나타났으며, 둘째, 향상된 청각적 변별능력은 일정 시 간이 지난 후에도 행동검사에서는 물론 청성유발전위검사에 서도 유지됨을 보였다. 본 연구 결과를 통해 짧은 훈련 시간으 로 유도된 빠른 신경학적 변화로 인하여 뇌가 빠르게 학습할 수 있다는 빠른 학습(fast learning)의 이론을 설명할 수 있었다 (Jancke et al., 2001).

단기 청능훈련은 아니지만, 선행연구에서는 집중적인 듣기훈 련이 청각적 능력의 기술 향상뿐만 아니라 다른 인지능력의 향 상을 이끈다고 보고하였다. Asal et al.(2018)의 연구에서는 노 인성 난청인을 대상으로 음조 순서화하기 훈련(pitch sequenc- 
ing training)을 통해서 음조 변별능력은 물론 청각 조합능력, 빠른 말 듣기능력 등의 능력이 모두 향상되었음을 증명하였고 이러한 청능훈련을 통한 일반화는 청각적 능력의 향상뿐만 아 니라 집중능력, 기억력 등의 능력 향상에서도 찾을 수 있다 (Murphy et al., 2015). Russo et al.(2005)은 학습장애인을 대상 으로 3개월 동안 소프트웨어를 이용한 청능훈련을 실시한 후 $/ \mathrm{ba} /$ 를 자극음으로 사용하여 청성뇌간반응(auditory brainstem response, $\mathrm{ABR})$ 을 측정하고 $\mathrm{ABR}$ 의 결과가 훈련 전후에 유의 하게 달라졌음을 보고하였다.

본 연구는 정상청력을 가진 대상자를 이용하여 매우 단기간 의 청능훈련이 학습전이와 훈련 효과가 유지됨을 증명하였다. 그러나 앞서 언급한 바와 같이 20대 정상청력 성인의 결과라는 점과 훈련 후 길지 않은 1 주일 뒤에 재확인했다는 제한점을 가 지고 있다. 집중적인 청능훈련이 필요한 대상자, 예를 들어 보청 기와 인공와우 착용 난청인, 학습장애인 등의 청각적 수행능력, 청각적 인지능력이 저하된 대상으로 한 효과적인 청능훈련의 기간, 방법 등에 대한 연구가 좀 더 필요하겠다. 또한 본 연구에 서는 다양한 어음을 사용하지 못하여 청능훈련의 효과를 다각 적으로 보지 못했다는 제한점이 있다. 단기 청능훈련을 통하여 여러 가지 다각적인 능력, 예를 들어 소음하 어음인지, 단기기 억, 집중력 등의 인지 영역에 관한 연구 또한 필요하겠다.

중심 단어 : 청능훈련·음전위 부정합·학습전이·유지효과.

\section{Ethical Statement}

The study was approved by the Institutional Review Board of Hallym University of Graduate Studies (HUGSAUD:\#615820).

\section{Acknowledgments}

The authors thank to the participants.

\section{Declaration of Conflicting Interests \\ There are no conflict of interests.}

\section{Funding}

This work was supported by the Ministry of Education of the Republic of Korea and the National Research Foundation of Korea (NRF-2019 S1A5A2A01039904).

\section{Author Contributions}

All authors contributed equally to this work. J.B. designed the experiments and wrote the paper. S.P. collected and analyzed the data, and wrote the paper. Also the authors discussed the results together.

\section{ORCID iDs}

Sulin Park

Junghwa Bahng

\section{https://orcid.org/0000-0002-3521-8419}

https://orcid.org/0000-0002-5265-3586

\section{REFERENCES}

Amitay, S., Irwin, A., \& Moore, D. R. (2006). Discrimination learning induced by training with identical stimuli. Nature Neuroscience, 9(11),
1446-1448.

Asal, S. I., Sobhy, O. A., \& Morsy, H. M. (2018). Effect of auditory temporal processing training on behavioral and electrophysiological functions in central presbycusis. The Egyptian Journal of Otolaryngology, 34(1), 68-75.

Beauchamp, C. M. \& Stelmack, R. M. (2006). The chronometry of mental ability: An event-related potential analysis of an auditory oddball discrimination task. Intelligence, 34(6), 571-586.

Ben-David, B. M., Campeanu, S., Tremblay, K. L., \& Alain, C. (2011). Auditory evoked potentials dissociate rapid perceptual learning from task repetition without learning. Psychophysiology, 48(6), 797-807.

de Melo, Â., Mezzomo, C. L., Garcia, M. V., \& Biaggio, E. P. V. (2018). Computerized auditory training in students: Electrophysiological and subjective analysis of therapeutic effectiveness. International Archives of Otorhinolaryngology, 22(1), 23-32.

Garrido, M. I., Kilner, J. M., Stephan, K. E., \& Friston, K. J. (2009). The mismatch negativity: A review of underlying mechanisms. Clinical Neurophysiology, 120(3), 453-463.

Han, W., Park, J., \& Bahng, J. (2013). The effects of auditory short-term training in passive oddball paradigm with novel stimuli. Korean Journal of Audiology, 17(3), 105-110.

Hedrick, M., Bahng, J., von Hapsburg, D., \& Younger, M. S. (2011). Weighting of cues for fricative place of articulation perception by children wearing cochlear implants. International Journal of Audiology, 50(8), 540-547.

Jäncke, L., Gaab, N., Wüstenberg, T., Scheich, H., \& Heinze, H. J. (2001). Short-term functional plasticity in the human auditory cortex: An fMRI study. Cognitive Brain Research, 12(3), 479-485.

Klatt, D. H. (1980). Software for a cascade/parallel formant synthesizer. The Journal of the Acoustical Society of America, 67(3), 971-995.

Kompus, K. \& Westerhausen, R. (2018). Increased MMN amplitude following passive perceptual learning with LTP-like rapid stimulation. Neuroscience Letters, 666, 28-31.

Kraus, N., McGee, T., Carrell, T. D., King, C., Tremblay, K., \& Nicol, T. (1995). Central auditory system plasticity associated with speech discrimination training. Journal of Cognitive Neuroscience, 7(1), 25-32.

Lee, S. \& Bahng, J. (2012). Cue weighting strategy of fricative perception in noise for normal hearing listeners. Audiology, 8(1), 52-60.

Murphy, C. F. B., Moore, D. R., \& Schochat, E. (2015). Generalization of auditory sensory and cognitive learning in typically developing children. PloS One, 10(8), e0135422.

Näätänen, R. (2000). Mismatch negativity (MMN): Perspectives for application. International Journal of Psychophysiology, 37(1), 3-10.

Näätänen, R. (2008). Mismatch negativity (MMN) as an index of central auditory system plasticity. International Journal of Audiology, $47 \mathrm{Suppl}$ 2, S16-S20.

Näätänen, R., Tervaniemi, M., Sussman, E., Paavilainen, P., \& Winkler, I. (2001). "Primitive intelligence" in the auditory cortex. Trends in Neurosciences, 24(5), 283-288.

Russo, N. M., Nicol, T. G., Zecker, S. G., Hayes, E. A., \& Kraus, N. (2005). Auditory training improves neural timing in the human brainstem. Behavioural Brain Research, 156(1), 95-103.

Tiitinen, H., May, P., Reinikainen, K., \& Näätänen, R. (1994). Attentive novelty detection in humans is governed by pre-attentive sensory memory. Nature, 372, 90-92.

Tremblay, K., Kraus, N., Carrell, T. D., \& McGee, T. (1997). Central auditory system plasticity: Generalization to novel stimuli following listening training. The Journal of the Acoustical Society of America, 102(6), 3762-3773.

Tremblay, K., Kraus, N., McGee, T., Ponton, C., \& Otis, B. (2001). Central auditory plasticity: Changes in the N1-P2 complex after speech-sound training. Ear and Hearing, 22(2), 79-90.

Wright, B. A. \& Zhang, Y. (2009). A review of the generalization of auditory learning. Philosophical transactions of the Royal Society B, Biological Sciences, 364(1515), 301-311. 